\title{
Prevalence and correlates of metabolic syndrome and its components in nearly 10 million participants of northwestern China: a cross-sectional study
}

\author{
yinxia su \\ Xinjiang Medical University \\ Wenli Li \\ Xinjiang Medical University \\ Yaoqin Lu \\ Xinjiang Medical university \\ Mingyue Xue \\ Xinjiang Medical University \\ Muyaseer Haireti \\ Xinjiang Medical University \\ Yuanyuan Li \\ Xinjiang Medical University \\ Shuxia Wang \\ Xinjiang Medical University
}

Hua Yao ( $\nabla$ yaohua01@sina.com )

\section{Research}

Keywords: comprehensive population, prevalence, metabolic syndrome, subgroup

Posted Date: July 30th, 2020

DOl: https://doi.org/10.21203/rs.3.rs-47843/v1

License: (c) (i) This work is licensed under a Creative Commons Attribution 4.0 International License. Read Full License 


\section{Abstract \\ Background}

The prevalence of metabolic syndrome (MetS) of comprehensive population are always lower than mono- population. However, studies on MetS and its components of it and its subgroups (different ages, genders, races, regions) based on big data and using a same diagnosis criterion are rare.

\section{Method:}

A total of 9,745,640 Chinese adults aged $\geq 18$ years in Xinjiang,the largest autonomous region of Multi-ethnic, were enrolled in the study. MetS was defined by modified Adults Treatment Panel (ATP III) criteria.Prevalence of metabolic syndrome and its components were calculated. To further explore the correlates of MetS and its components logistic regression were used.

\section{Results}

The overall prevalence of MetS was $20.85 \%$ [Sex: $20.06 \%$ in female, $21.56 \%$ in man; Age: $39.22 \%$ in 60 year older followed by $40-59$ year $26.32 \%$ and $18-$ 39 years 9.56\%; Ethnicity: 28.19\% in Hui followed by Han (26.39\%), Uyghur(18.56\%), Other(18.61\%), Kazak(17.98\%), Mongolian (17.87\%), Kyrgyz(14.44\%)], living in city and town (23.03\%) or north(24.78\%) had higher prevalence of MetS than living in rural (19.94\%) and South (17.66\%). Although the prevalence of hypertension, smoking, drinking and lack of physical activity in Kyrgyz, Mongolian and Kazakh were higher than those of other ethnic groups, the risk of MetS was lower than that of other. The results also showed that although their risk of central obesity and hypertension was higher than that of Han, Hui, Uygur and other, the risk of high-TG, low HDL-C and Elevated-FPG was significantly lower than that of other ethnic groups. Among them, the Mongolian had the lowest risk of high-TG and low-HDL-C, while the Kazakh had the lowest risk of elevated-FPG. In addition, except that the risk of central obesity in males was lower than that in females, the other components of males were higher than those in females, but the risk of MetS was lower than that in females. The risk of MetS and its components in the elderly was significantly higher than that in the young, and physical activity did not show reduce the risk of MetS in the general population.

\section{Conclusion}

The reason why the prevalence of MetS in the comprehensive population is lower than that in most mono-population may be that some subgroups of the population have the ability to resist risk factors in terms of genetic structure such as Kyrgyz, Mongolian, Kazak, and the influence in this aspect may exceed that of lifestyle. Within each subgroup, the prevalence of MetS is still increasing. Central obesity is an important risk factor for women with MetS. Elevated-FPG and high-TG are the most important risk factors of MetS in Han, Hui. Climate and lifestyle are the main causes of MetS in northern Xinjiang and city and town residents.

\section{Background}

The Metabolic syndrome (MetS) is characterized by multiple metabolic risk factors in the state of gathering of individuals, including central obesity, diabetes, or sugar impaired regulation, dyslipidemia, hypertension and insulin resistance.(IR), hyperuricemia and microalbuminuria[1]. Patients with the metabolic syndrome are at increased risk for developing type 2 diabetes mellitus and cardiovascular mortality and morbidity[2].The link between metabolic syndrome and increased risk of multiple chronic diseases (eg, cardiovascular disease, type 2 diabetes, arthritis, chronic kidney disease, schizophrenia) and of early death have been reported for many decades[2-4].

It is estimated that about 20-30 percent of the world's population suffers from MetS, and the prevalence is on the rise[5]. Even if the same criteria are used, the results of MetS prevalence vary from place to place. Based on the the National Cholesterol Education Program (NCEP - Adult Treatment Panel III (ATP III) the prevalence of MetS of adults in aged $\geq 20$ years of the United States was $34.7 \%[6]$, in Canada, nearly $25 \%$ of the multi-ethnic adult population was found to be afflicted with MetS[7]; in sub-Saharan Africa, multi-ethnic participants aged $\geq 16$ years was 17.1\%.[8],. In Australia, the prevalence of MetS was $21.7 \%$ aged $\geq 25$ years in national wide survey[9]. The latest national meta-analysis in 2016 estimated the prevalence of MetS in China at 24.5\%,[10] but another study show lower prevalence of MetS in rural of northeastern Chinese(24\%). Muti-ethnic population aged $\geq 20$ years showed even more lower prevalence MetS (15.9\%) in rural of northwestern Chinese in the study of Heng Guo's research group[11]. The prevalence of MetS in Indonesia is 21.66\% among provinces and ethnic groups[12]. As to mono-population, Xyi Wang etl. reported $30.0 \%$ MetS prevalence among Han aged $\geq 18$ years in Zhe jiang province[13], China; in aged 19-65 adults in Brazil was 29.6\%[14], a study on Han in northeas China showed the overall prevalence of Mets was 41.3\%.[15]. A comprehensive population always have lower prevalence need to explored. A comprehensive understanding of MetS in adults may be important for the specific direction of prevention strategies. MetS components such as hypertension, diabetes and dyslipidemia are major and modifiable risk factors for major chronic diseases; therefore, it is important for policy makers to track changes in MetS prevalence in order to obtain an insight into the extent of MetS burden, and to explore new risk factors. In recent years, studies on metabolic syndrome in different regions and different population of China have been done, but most of them have different standards[16-19] and results were inconsistent, possibly because of small sample sizes, short age span or regional factors. Few studies based on big data to analyze the epidemiological characteristics and risk factors of metabolic syndrome in subgroups of a comprehensive population at the same time according to the same standard. 
Since it is found that the proportion and distribution of body fat in Asians are different from those in North America and Europe[20, 21], it is clear that the definition of obesity applicable to the Western population does not apply to the Asian population. The Harmonized criteria have defined Asian cut-offs for central obesity (waist circumference: $\geq 90 \mathrm{~cm}$ for males; $\geq 80 \mathrm{~cm}$ for females) and reduced cut-off for hyperglycemia ( $\geq 5.6 \mathrm{mmol} / \mathrm{L}$, instead of 6.1 $\mathrm{mmol} / \mathrm{L}$ in the NCEP-ATP III). (modified Adults Treatment Panel (ATP区) criteria in 2005 a harmonized definition in 2009, which was reported most suitable for Asians[22, 23].The prevalence of MetS is dependent on a variety of non-modifiable of gene structure (gender, age, ethnicity) and modifiable (lifestyle, diet) risk factors. These factors are known to, directly or indirectly, influence MetS among the populations. Studies indicated the significant influence of lifestyle habits on the prevalence. But the results are inconsistent. Also the relationship of lifestyle behaviors with MetS among major ethnicities was not found in some studies[24]. Maybe non-modifiable factors of some subgroups have more influences on MetS.

To obtain a comprehensive and accurate understanding of Chinese comprehensive population This study is based on a big data of nearly 10 million people aged 18 years older, used Harmonized ATP区, to analyze the prevalence and its risk factors of metabolic syndrome and its components by ages, ethnicity, regions and education to provide a basis for preventive interventions against MetS and related diseases in China.

\section{Methods}

\section{Study design and population}

The study include data from 2019 of a free medical examination program of Xinjiang, the largest autonomous muti-ethnic region in China, which has launched since September 2016. All residents of Xinjiang can take part in this free annual medical examination organized and funded by the government. It contains socioeconomic variables, status of medical resource utilization, consultation and national health screening results, and status of clinic. In 2019 , This representative sample we analyzed covering about $57.4 \%$ of the whole Xinjiang population aged $\geq 18 y e a r s$ old. $16,979,107$ residents participated this physical examination in 2019. After excluding individuals who aged $<18$ years $(n=6,333,609)$, who were unwilling to participate ( $n=$ $457,108)$, whose data had missing MetS components (WC, BP, FBG, TG or HDL) data $(n=245755)$, pregnancy in women ( $n=96,923)$ and deleted the data of duplicates $(n=25,638)$ and outlier $(n=74,362)$, a final target of $9,745,640$ subjects (females, $5,134,110)$ were finally analyzed (Figure 1$)$.

\section{Data collection and measurement}

At each health check site, uniformly trained staff collected data in accordance with the standards at the examination centers of local health stations or community clinics in participants' residential areas.

Demographic data and lifestyle risk factors, such as age, sex, marital status, education; Smoking status, alcohol consumption, physical activity by collecting in frequency. Information above were recorded through face to face interview. Waist circumference was measured to $1 \mathrm{decimal}$ point $(0.1 \mathrm{~cm})$, from the middle point between the lowest rib to the highest iliac crest line when the subject exhaled, using a measuring tape. Body mass index (BMI) was calculated by dividing weight $(\mathrm{kg})$ by height squared $\left(\mathrm{m}^{2}\right)$. Blood pressure was measured three times using an automated electronic device $(\mathrm{OMRON}$ Model HEM-7071, Omron Company) after the subject had been sitting down for 5 min with a tourniquet placed on his or her left arm; the mean value for the 2 nd and 3 rd blood pressure readings was considered the final blood pressure value.

Blood was extracted from the antecubital vein subsequent to at least $8 \mathrm{~h}$ of fasting, refrigerated, and analyzed within $4 \mathrm{~h}$ of being moving to locally qualified laboratories. TG, HDL-C, LDL-C and FPG were tested using instruments and guidelines of the same model and calibrated regularly. All study laboratories successfully completed a standardization.

\section{Quality control}

This big scale physical examination project has been going on for 4 years and has good experience to ensure the reliability of the data and a well-defined, comprehensive quality control was implemented. The national physical examination program involves 1315 medical institutions of different sizes. All community health staffs participating in the project are regularly trained in the operation of physical examination norms formulated by the Xinjiang Health Commission of autonomous Region. The training includes questionnaire survey, physical measurement, laboratory test and data entry.

\section{Definition of MetS}

In the present study, we used the Harmonized criteria from the National Cholesterol Educational Program (the revised NCE-PATP III for Asians in 2009[25]) to define MetS, which requires the presence of three or more of the following five MetS components: 1) Central obesity (according to the Asian crowd standard, waist circumference (WC $\geq 90 \mathrm{~cm}$ in men and $\geq 80 \mathrm{~cm}$ in women)). Compared with Europids, an expert consultation for WHO indicated that cut points in the Asian population should be $90 \mathrm{~cm}$ for men and $80 \mathrm{~cm}$ for women. 2) Raised serum triglycerides (high-TG) defined as TG $\geq 1.7 \mathrm{mmol} / \mathrm{L}$ ( 150 $\mathrm{mg} / \mathrm{dL}$ ); 3) low high-density lipoprotein cholesterol (low-HDL-C) defined as HDL-C $<1.0 \mathrm{mmol} / \mathrm{L}$ (40 mg/dL) for males and $<1.3 \mathrm{mmol} / \mathrm{L}$ (50 mg/dL) for females; 4) high blood pressure (high-BP): (SBP $\geq 130 \mathrm{mmHg}$ or DBP $\geq 85 \mathrm{mmHg}$ or taking antihypertensive drugs); 5) Raised fasting blood sugar (hyperglycemia, high-FBG) defined as $\geq 5.6 \mathrm{mmol} / \mathrm{L}(100 \mathrm{mg} / \mathrm{dL})$ or taking hypoglycemic drugs.

\section{Statistical Analysis}

All data analyses were conducted using R version4.0.2 Copyright (C) 2020 The R Foundation for Statistical Computing Platform. Variables were summarized using means for continuous data and percentages or proportions for categorical data. The $95 \%$ Cls were calculated for means, percentages, or proportions. The Student $t$ test, one-way ANOVA and Rao-Scott $\chi^{2}$ test were used to assess the differences across groups for continuous and 
categorical variables respectively. A multivariable logistic regression analysis was conducted to evaluate the associated factors for MetS and its components. All tests were two tailed, and $P<0.05$ was considered statistically significant.

\section{Results}

\section{General population characteristics}

Of the $9,745,640$ participants, $47.32 \%$ were men, 52.68\% were female邓primarily Uyghur (57.93) followed by Han (25.47\%), Kazak (8.21\%), Hui (4.15\%), Kyrgyz (1.17\%), Mongolian ( $0.81 \%$ ) and others (2.275). Age was divided into three stages, $18-39$ years old old (45.27\%) followed by $40-59$ years old old (38.29\%) and over 60 years old (16.43\%). The majority $(70.49 \%)$ of subjects were come from rural, $29.51 \%$ were come from city and town. Among the subjects of this study, living in southern Xinjiang (55.22\%) were more than those in northern Xinjiang (44.78\%), and those with education level of 6 years or less $(58.79 \%)$ are more than 7 years or more $(41.21 \%)$ (Table 1$)$.

\section{Subjects' anthropometry, blood test results and health behavior characteristics}

Subjects' anthropometry and blood test results and health behavior characteristics are shown in Table 2 which shows the average of BMI, WC, SBP, DBP, LDL-C, HDL-c, TC, FBG and the percentage of smoking, drinking and physical activity. The results show that all the indexes were significantly different among sex, age, ethnicity, household registration, geographical location and education $(p s<0.0001)$.

Among In two categories of variables, In terms of sex, except that the HDL-C is lower than that of female, the other indexes of male are higher than that of female $(P<0.0001)$, Smoking and drinking accounted for the most in the 40-59 age group, and physical activity the most in 60 years and older; in terms of household registration, except for WC and FBG, the other indexes are higher in city and town than in rural $(P<0.0001)$, and people in rural have more smoking prevalence while in city and town have more drinking and physical activity $(P<0.0001)$; in terms of residential geographical location, all indexes are higher in northern Xinjiang than in southern Xinjiang, and more northerners drinking while more southerners smoking and doing physical activity $(P<0.0001)$. In terms of education, all indexes of $\geq 7$ years was higher than that of $\leq 6$ years, except that HDL-C was equal to it and $\geq 7$ years had more smokers, drinkers and fewer regular physical activity than those of $\leq 6$ years $(P<0.0001)$.

Among the multi-classified variables, in terms of age, all the other indexes were the lowest except the tallest height in 18-39 years old, the highest in weight, BMI and TG in 40-59 years old old, were the highest in 60 years and older $(P<0.0001)$, and age in 40-59 years old old had more smokers and drinkers while in 60years and older have more people doing activity $(P<0.0001)$.

In terms of ethnicity, as to Uygher, TC were lowest and all else indicator were in middle lower level; Han, TC highest, and the other indexes were at a high level. Kazak, SBP and HDL-c highest, TG lowest and The other indexes were at a high level; Hui, FBG the highest, and the other indexes were at a high level; Kyrgyz, LDL-c the highest, weight, WC, SBP and DBP the lowest and other indexes are at a low level. Mongolian, height, weight, BMI, WC, DBP and HDL-C are the highest and other indexes are at a low level, $(P<0.0001)$. As to lifestyle, Kyrgyz have most drinkers followed by Mongolian, Kazak, Uyghur, Han and Hui; Kyrgyz also have least people doing physical activity followed by Uyghur, Kazak, Hui, Mongolian and Han.

\section{Prevalence of metabolic syndrome}

The prevalence of MetS was significantly different between sex, household registration, residential geographical location and education with higher in male (21.60\%), age in 60 years and older (39.22\%), city and town (23.03\%), North (24.78\%), 7 years or more education (24.54\%); There were significant differences in ages. Prevalence was $9.56 \%$ among aged 18 - 39 years and increased to $39.22 \%$ among $\geq 60$ years old. There were significant differences in prevalence between ethnicity with the highest in Hui (28.19\%), followed by Han (27.3\%), other (18.61\%), Uyghur (18.56\%), Mongolian (17.98\%), Kazak (17.87) and Kyrgyz (14.44) (Talbe3).

The prevalence of five MetS components showed that central obesity prevalence was highest (51.71\%), followed by high-FPG (26.59\%), high-TG (23.71), high-BP (23.16\%), and low-HDL-C (4.68\%). As to subgroup of five components prevalence, Central obesity and high-FPG were more prevalent in women than in men, whereas high-TG, low-HDL-C, high-BP were more common in men than in women. As to age, the prevalence of individual components of the MetS were remarkably higher in 60 years and older compared with other ages, except for central obesity and high-TG highest in 40-59 years old. The prevalence of high-FPG, high- TG and low-HDL-C were remarkably higher in Hui (35.68\%, 26.04\% and $8.09 \%)$ and Han $(32.69 \%, 27.75 \%$ and $8.11 \%)$ than other ethnic groups. The prevalence of central obesity and high-BP of Mongolian were remarkably higher than ethnic groups, which were $55.94 \%$ and $27.18 \%$. As to household registration and geographical location, the prevalence of individual components of the MetS were remarkably higher city and town, north than in rural and south, except for central obesity and high-FPG higher in rural than in city and town, low-HDL-C higher in south than north. As to education, the prevalence of individual components of the MetS were remarkably higher among $\geq 7$ years than among $\leq 6 y e a r s$.

The prevalence of MetS and its components elevated in smokers and drinker except for central obesity higher in nonsmokers, nondrinkers and high-BP higher in nonsmokers. The prevalence of MetS and its components elevated in participants with physical activity level (all $P<0.0001 ;$ Table 2).

\section{Influential factors associated with MetS and its individual components}

The results of logistic regression analysis performed to identify factors affecting MetS and its individual components, are shown in Figure2-8. The risk to have MetS was 1.19 (1/0.84) times less in women relative to men (95\% confidence interval [21] 0.84-0.85, $P<0.0001)$, 3.25 and 5.93times higher in 40$59 y e a r s, \geq 60$ years old relative to 18-39years (95\% Cl: 3.25-3.38, 5.91-5.97, $P<0.0001)$; 1.35, 1.27, 1.63 times higher in Uyghur, ,Han, Hui relative to Kyrgyz 
(95\%Cl: $1.33-1.37,1.24-1.29,1.61-1.67, P<0.001)$; and ,in contrast, 1/0.97, 1/0.91 time lower than in Kazak, Mongolian (95\%Cl: 0.96-0.99, 0.89-0.94) and 1.04 times higher in city and town relative to rural subjects (95\% $\mathrm{Cl}: 1.03-1.04, P<0.001)$, and 1.34 times higher in north residents than in south(95\% $\mathrm{Cl}$ : $1.33-1.34, P<0.001)$; and 1/0.98 times lower in 7 years and more education than in 6 years and less education subjects (95\% $\mathrm{Cl}$ : $0.98-0.99, P<0.001)$. 1.15,1.12 times higher in smokers and drinkers (95\% Cl: 1.15-1.16, 1.11-1.12, $P<0.001)$ (Fig.2).

The risk of central obesity was $2.38(1 / 0.42)$ times higher in women relative to men ( $95 \% \mathrm{Cl}: 0.42-0.42, P<0.001) ; 2.46,2.56$ times higher in $40-59$ years old, $\geq 60$ years old relative to $18-39$ years old $(95 \% \mathrm{Cl}: 2.45-2.47,2.56-2.58, P<0.001)$. Among ethnic groups, Uyghur and Mongolian has more risk to have central obesity [OR $(95 \% \mathrm{Cl}): 1.27(1.25-1.29), 1.16(1.14,1.18)]$, while Han has less risk than others [OR $(95 \% \mathrm{Cl}): 0.79(0.79-0.81)$ ]. 1/0.98 times lower in 7 years and more education than in 6 years and less education subjects $(95 \% \mathrm{Cl}$ : 0.98-0.99, $P<0.001)$. Living in city and town, Northerners, smokers and drinkers have more risk to have central obesity (Fig.3).

The risk of high-TG levels was 1.54 times higher in men relative to women (95\% Cl: $1.53-1.54, P<0.001) ; 1.72,1.65$ times higher in $40-59$ years old, $\geq 60$ years old relative to $18-39$ years old ( $95 \% \mathrm{Cl}$ : 1.53-1.54, 1.71-1.72, $P<0.001)$. Among ethnic groups, Hui and Han has more risk to have high-TG than other ethnic groups [OR (95\% Cl):1.67(1.64-1.70), 1.62(1.58,1.64)], while Mongolian and Kazak have less risk than others. 1/0.94 times lower in 7 years and more education than in 6 years and less education subjects ( $95 \% \mathrm{Cl}$ : 0.94-0.94, $P<0.001)$. Living in city and town, Northerners, smokers and drinkers have more risk to high-TG (Fig.4).

The risk of low-HDL-C was 1.93 times higher in men relative to women (95\% Cl: 1.92-1.94, $P<0.001) ; 0.97,1.15$ times higher in $40-59$ years old, $\geq 60$ years old relative to $18-39$ years old $(95 \% \mathrm{Cl}$ : 0.96-0.97, 1.14-1.16, $P<0.001)$. Among ethnic groups, Hui and Han has more risk to have low-HDL-C than other ethnic groups [OR (95\% Cl): 1.11(1.08-1.14), 1.07(1.05-1.10)], while Mongolian and Kazak had remarkably less risk than others. 1.09 times higher in 7 years and more education than in 6 years and less education subjects $(95 \% \mathrm{Cl}: 1.08-1.10, P<0.001)$. Living in city and town, drinkers have more and Northerners, smokers have less risk to low-HDL-C (Fig.5).

The risk of high-FPG was 1.15 times higher in men relative to women ( $95 \% \mathrm{Cl}: 1.14-1.15, P<0.001) ; 2.10,3.86$ times higher in $40-59$ years old, $\geq 60$ years old relative to $18-39$ years old ( $95 \% \mathrm{Cl}$ : 2.10-2.11 3.83-3.86, $P<0.001)$. Among ethnic groups, Hui and Han has more risk to have high-FPG than other ethnic groups [OR (95\% Cl): 1.25(1.23-1.26), 1.04(1.02-1.05)], while Mongolian and Kazak had less risk than others. 7 years and more education subjects had less risk than in 6 years and less education subjects [95\% Cl: 0.90(0.90-0.91), $P<0.001]$. Living in city and town, drinkers have less and Northerners, smokers have more risk to high-FPG (Fig.6).

The risk of high-BP was 1.23 times higher in men relative to women ( $95 \% \mathrm{Cl}$ : $1.23-1.24, P<0.001) ; 5.37,17.81$ times higher in $40-59$ years old, $\geq 60$ years old relative to $18-39$ years old $(95 \% \mathrm{Cl}$ : $5.33-5.38,17.75-17.93, P<0.001)$. Among ethnic groups, Kazak and Mongolian has more risk to have high-BP than other ethnic groups [OR (95\% Cl): 1.28(1.26-1.31), 1.15(1.12-1.17)], while Han and Hui had less risk than others. 1.19 times higher in 7 years and more education than in 6 years and less education subjects ( $95 \% \mathrm{Cl}$ : 1.18-1.19, $P<0.001)$. Living in city and town, smokers have less and Northerners, drinkers have more risk to high-BP (Fig.7).

\section{Discussion}

This study was carried out in Xinjiang, a typical multi-ethnic province. Xinjiang is the largest province in China, with an area of 1.66 million square kilometers, accounting for $1 / 6$ of China's total land area. There are 55 ethnic groups in Xinjiang, with a resident population of 24.8676 million. The top 6 ethnic groups in Xinjiang are Han, Uygur, Kazakh, Hui, Mongolian and Kyrgyz. Xinjiang is divided into northern and southern Xinjiang because of Tianshan Mountains. Due to the geographical location and the topography of the Taklimakan Desert, which is the second largest desert in the world in southern Xinjiang, the climate of north and south is different with temperate continental semi-arid and t arid climate respectively. Geographical environment and ethnic origin may affect the occurrence and development of human diseases, so this study not only analyzed the common demographic characteristics, but also adds the analysis and study of northern and southern Xinjiang and six ethnic groups. Although the objects of this study were a comprehensive and multi-ethnic population, considering the number of the sample were huge, the analysis results of it and its subgroups would be still reliable.

This study showed the prevalence of MetS in this large comprehensive muti-ethnic population in Xinjiang was $20.85 \%$, which is consistent with that of the whole world[26]. This rate is lower than those of Western and United States[6] and other Asian countries and Chinese studied on other area of China but higher than rural areas in Xinjiang of a study also conducted in multi-ethnic adult in 2017(14.43\%)[11]. It is worth noting that results of previous studies for a large number of mono-population or ethnic groups showed that the prevalence of MetS are always higher than that of comprehensive population or multi-ethnic population like this, which suggests that there may be some subgroups of people whose prevalence of MetS always lower than others making the overall values reduction. This study found that Kazakh, Mongolian and Kyrgyz may be such subgroups.

Interestingly, the results showed the Kyrgyz with the lowest prevalence of MetS had the highest smoking and drinking rate and the lowest physical activity rate, so it seems that lifestyle do not play a major role in determining the prevalence of MetS in Kyrgyz, similar phenomenon happed on Kazak and Mongolian. Compared with other ethnic groups, they have higher BMI, WC, SBP and lower TC and TG. So, we speculate that this phenomenon is related to the genetic structure of the ethnic origin. From the study of MetS components, we found that they had higher HDL-C than that of other ethnic groups, but their high-TG risk was lower than other ethnic groups, indicating that there may be hereditary factors working, liking different gene structure or something and genetic factors may enable the body to evolve some anti-disease ability. Coincidentally, in 2018, Ying-Yu Zhang et al.[27] identified a rare frame shift variant in the LIMA1 (also known as EPLIN or SREBP3) gene from Kazakh ethnicity with inherited low LDL-C and reduced cholesterol absorption, which is consistent with our results. Also, many studies have proved that Kazak, Mongolian and Kyrgyz have closer gene relationships than with others[28-31].

Page 5/16 
Therefore, it is possible that Mongolian and Kyrgyz people also have this kind of unique genetic structure. This is worthy of further study to explore the relationship between unique genetic structure mentioned above and diseases for prevention and knowing the mechanism.

In terms of gender, the prevalence of MetS syndrome in women is lower than that in men, but multivariate regression analysis shows that the risk is higher than that in men adjusting age, ethnic group, region and lifestyle. It is consistent with some researches[11, 15, 32], among them some reported postmenopausal status may have effects on MetS because of insulin resistance and central obesity after menopause[33] and the results also indicated that central obesity was one of the main risk of MetS. It is suggested, especially women, should pay attention to the prevention of central obesity.

From the point of view of whether the household registration is urban or rural, the prevalence and risk of MetS of urban residents are higher than those of rural residents. With the development of urbanization, people's lifestyle and diet are changing rapidly. From the univariate and multivariate analysis of the influencing factors and MetS components, we could see that although there were more people doing physical activity in city and town and less smokers, the rate of MetS among city and town residents was significantly higher than that of rural residents. Maybe that was because more drinkers in city and town and so they were more likely to suffer from high-TC, low-HDL-C, which makes them more likely to have MetS as some studies[34-36]showed, so alcohol restriction should be emphasized in the health education of city and town residents.

From the point of view of Geographical location, the prevalence of MetS in northern Xinjiang is much higher than that in southern Xinjiang, and the risk to have MetS was also higher than that in southern Xinjiang residents. The results showed Northerners were more likely to suffer from central obesity, highTG, high-BP and high-BFG, but the risk of high- and low-density lipoprotein is lower than that in southern. This may be due to the fact that residents in northern Xinjiang tend to eat high-calorie food and drink more alcohol than those in southern Xinjiang because of colder climate. Outdoor exercise is less than that in the south, which is consistent with the results of previous studies on MetS of north and south residents, but southerners are more likely to develop low-HDL-C than northern residents maybe relate to the Kazakh, Mongolian and other ethnic groups with anti-lipid genes living in northern Xinjiang, which need to be further studied.

From the perspective of educational background, the prevalence of MetS in subjects with $\geq 7$ years of educational experience was higher than that of those $\leq 6$ years of education, but after adjusting for age, ethnic areas and living habits, the risk was lower than those who had received education for $\leq 6$ years. Some studies have shown that the higher level of education[37] the higher the score of health literacy, but the results of this study show that the rate of smoking and drinking is higher, and the rate of regular exercise is lower than that of those with low level of education. in the analysis of various components of metabolic diseases, the risk was higher in subjects of low level of education, and the risk of central obesity, high-TG and high-FBG was lower than that of low level of education. The reasons need to be further explored.

Interestingly, there are inconsistencies in the results of this big data's analysis of common bad lifestyle such as smoking, drinking and lack of exercise. From the prevalence of MetS, smokers, drinkers and regular exercise people are lower than non-smokers, non-drinkers and lack of exercise. In multivariate analysis, the risk of MetS in smokers and drinkers is higher than that in non-smokers and non-drinkers, indicating that the risk of MetS was greatly affected by other factors, such as gender, ages, while exercise people have an increased risk of MetS. In short, on the whole, we cannot find the rule of the relationship between lifestyle and MetS. This may be related to the complex composition of subgroups within the big comprehensive population, which is worthy of further exploration and study from the perspective of genetics and etiology combined with prevention strategies.

\section{Conclusion}

The results of genetic and environmental both work during the occurrence and development of MetS and its components.

The prevalence of MetS in Kazakh, Mongolian and Kyrgyz was lower than other ethnic groups even if the proportion of risk factors and the rate of bad lifestyle was higher. The regular relationship between lifestyle and common risk factors could not be found in a large-scale comprehensive multi-ethnic population analysis. In addition, the prevention of central obesity should be strengthened, especially for middle-aged and elderly women; Han and Hui should pay special attention to the prevention of hyperglycemia; northern Xinjiang residents should strengthen exercise, and urban residents should pay special attention to restricting alcohol consumption.

In addition, it is worthwhile to further study the relationship between MetS and gene structure of Kazakh, Mongolian and Kyrgyz in order to explore the mechanism of MetS occurrence and development to provide more reliable evidence for prevention strategies.

\section{Abbreviations}

MetS, metabolic syndrome; WC, waist circumference; SBP, DBP, systolic-diastolic blood pressure; TC, total cholesterol; TG, triglyceride; HDL-C, high-density lipoprotein; LDL-C, low-density lipoprotein; FPG, fasting plasma glucose; ATP III, modified Adults Treatment Panel.

\section{Declarations}

\section{Acknowledgments}

We thank all the staffs from Health Commission of autonomous Region and 1315 medical institutions of local health Centers for their collection of data and blood samples. We also thank all the study participants for their participation and contribution. 
Ethical approval and consent to participate

The Medical Ethics Committee of the First Affiliated Hospital of Xinjiang Medical University approved the study protocol (20190225-105). Informed written consent was obtained from all the final target study participants.

Authors' contributions

HY and SX W designed the study; YX S, YQ L and WL L carried out the initial analyses, drafted the initial manuscript, and revised the manuscript; $M Y X$, $\mathrm{MH}$, and $Y Y \mathrm{~L}$, contributed to the data interpretation and reviewed the manuscript. All authors read and approved the final manuscript

Funding

This work is funded by grant 2018E02057 from the Science and Technology Support Project, Department of Science and Technology of Xinjiang Uygur Autonomous Region; grant 81960608 from District Science Foundation program, National Natural Science Foundation State Natural Science Funds Commission, China.

Availability of data and materials

The datasets analyzed during the current study are available from the corresponding author on reasonable request.

Consent for publication

Not applicable.

Competing of Interest

The authors declare that they have no conflict of interest.

\section{References}

1. Grundy SM, Cleeman JI, Daniels SR, Donato KA, Eckel RH, Franklin BA, Gordon DJ, Krauss RM, Savage PJ, Smith SC, Jr., et al: Diagnosis and management of the metabolic syndrome: an American Heart Association/National Heart, Lung, and Blood Institute scientific statement.Curr Opin Cardiol 2006, 21:1-6.

2. Lekoubou A, Ovbiagele B, Markovic D, Sanossian N, Towfighi A: Age, sex, and race/ethnic temporal trends in metabolic syndrome prevalence among individuals with myocardial infarction or stroke in the United States.J Neurol Sci 2017, 376:24-28.

3. Moore JX, Chaudhary N, Akinyemiju T: Metabolic Syndrome Prevalence by Race/Ethnicity and Sex in the United States, National Health and Nutrition Examination Survey, 1988-2012.Prev Chronic Dis 2017, 14:E24.

4. Z D, A J, M C, T V, E K, B M: Associations of Cardiovascular and All-Cause Mortality with Metabolic Syndrome in Hemodialysis Patients: A Prospective Single-Center Study.Medicina (Kaunas, Lithuania) 2019, 55.

5. S ON, L OD: Metabolic syndrome: a closer look at the growing epidemic and its associated pathologies. Obesity reviews : an official journal of the International Association for the Study of Obesity 2015, 16:1-12.

6. Hirode G, Wong RJ: Trends in the Prevalence of Metabolic Syndrome in the United States, 2011-2016.JAMA 2020, 323:2526-2528.

7. SS A, Q Y, H G, E L, R J, V V, K T, B D, P M, S Y: Relationship of metabolic syndrome and fibrinolytic dysfunction to cardiovascular disease.Circulation 2003, 108:420-425.

8. H JF-W, AP K, KAC M, C A: Prevalence of metabolic syndrome in sub-Saharan Africa: Asystematic review and meta-analysis.Nutrition, metabolism, and cardiovascular diseases : NMCD 2020, 30:547-565.

9. AJ C, DJ M, PZ Z, T W, JE S: The metabolic syndrome in Australia: prevalence using four definitions.Diabetes research and clinical practice 2007, 77:471-478.

10. Li R, Li W, Lun Z, Zhang H, Sun Z, Kanu JS, Qiu S, Cheng Y, Liu Y: Prevalence of metabolic syndrome in Mainland China: a meta-analysis of published studies.BMC Public Health 2016, 16:296.

11. H G, X G, R M, J L, Y D, M Z, J Z, L M, J H, Y Y, et al: Prevalence of Metabolic Syndrome and its Associated Factors among Multi-ethnic Adults in Rural Areas in Xinjiang, China.Scientific reports 2017, 7:17643.

12. EH H, TS N: Prevalence and distribution of metabolic syndrome and its components among provinces and ethnic groups in Indonesia.BMC public health 2019, 19:377.

13. X W, D H, L T, J S, Z Y: Comparative study on prevalence of metabolic syndrome based on three criteria among adults in Zhejiang province, China: an observational study.BMJ open 2020, 10:e035216.

14. F dCV, J B, N B, J S-S: Prevalence of metabolic syndrome in Brazilian adults: a systematic review.BMC public health $2013,13: 1198$.

15. Z D, L X, S L, L J, Y T, B Z, H Y, M L, S Y, Y S: Prevalence and determinants of metabolic syndrome based on three definitions in rural northeast China.Public health nutrition 2020:1-8. 
16. Li H, Guo M, An Z, Meng J, Jiang J, Song J, Wu W: Prevalence and Risk Factors of Metabolic Associated Fatty Liver Disease in Xinxiang, China.Int J Environ Res Public Health 2020, 17.

17. Zhang Z, Fan S, Xue Z, Yuan J, Zhou Z, Wang T, Liu J, Bawudun A, Nurmamat N, Wang Y, Yang Z: Evaluation of the appropriate predictive contributor and diagnostic threshold for the cardio-metabolic syndrome in Chinese Uyghur adults.BMC Public Health 2019, 19:613.

18. Zhu Y, Zheng H, Zou Z, Jing J, Ma Y, Wang H, Luo J, Zhang X, Luo C, Wang H, et al: Metabolic Syndrome and Related Factors in Chinese Children and Adolescents: Analysis from a Chinese National Study.J Atheroscler Thromb 2020, 27:534-544.

19. Y L, Z M, S Z, Y L, S L, Z Z, X D, C C, T D, W Z, et al: Prevalence of metabolic syndrome in China: An up-dated cross-sectional study.PloS one 2018, 13:e0196012.

20. Appropriate body-mass index for Asian populations and its implications for policy and intervention strategies.Lancet (London, England) 2004, 363:157-163.

21. Deurenberg P, Deurenberg-Yap M, Guricci S: Asians are different from Caucasians and from each other in their body mass index/body fat per cent relationship.Obes Rev 2002, 3:141-146.

22. Du Z, Xing L, Liu S, Jing L, Tian Y, Zhang B, Yan H, Lin M, Yu S, Sun Y: Prevalence and determinants of metabolic syndrome based on three definitions in rural northeast China.Public Health Nutr 2020:1-8.

23. SP I, A R, QK F, HL S, WY O, KA K: Relationship of sociodemographic and lifestyle factors and diet habits with metabolic syndrome (MetS) among three ethnic groups of the Malaysian population.PloS one 2020, 15:e0224054.

24. AK T, RA D, ST Y: Ethnic disparities in metabolic syndrome in malaysia: an analysis by risk factors.Metabolic syndrome and related disorders 2011, 9:441-451.

25. KG A, RH E, SM G, PZ Z, JI C, KA D, JC F, WP J, CM L, SC S: Harmonizing the metabolic syndrome: a joint interim statement of the International Diabetes Federation Task Force on Epidemiology and Prevention; National Heart, Lung, and Blood Institute; American Heart Association; World Heart Federation; International Atherosclerosis Society; and International Association for the Study of Obesity.Circulation 2009, 120:1640-1645.

26. MG S: The Global Epidemic of the Metabolic Syndrome.Current hypertension reports 2018, 20:12.

27. YY Z, ZY F, J W, W Q, G B, J L, YJ M, SY G, HY, SY J, et al: LIMA1A variant promotes low plasma LDL cholesterol and decreases intestinal cholesterol absorption.Science (New York, NY) 2018, 360:1087-1092.

28. Y G, C C, X J, W C, Y W, H W, T K, Y M, B Z: Autosomal DIPs for population genetic structure and differentiation analyses of Chinese Xinjiang Kyrgyz ethnic group.Scientific reports 2018, 8:11054.

29. T M, LP Z, YS L, JG C, HT M, JW Y, BF Z: 24 Y-chromosomal STR haplotypic structure for Chinese Kazak ethnic group and its genetic relationships with other groups.International journal of legal medicine 2016, 130:1199-1201.

30. Y G, C C, T X, W C, H M, X J, B Z: Forensic efficiency estimate and phylogenetic analysis for Chinese Kyrgyz ethnic group revealed by a panel of 21 short tandem repeats. Royal Society open science 2018, 5:172089.

31. YG Y, QP K, CY W, CL Z, YP Z: Different matrilineal contributions to genetic structure of ethnic groups in the silk road region in china.Molecular biology and evolution 2004, 21:2265-2280.

32. S Y, X G, H Y, L Z, Y S: An update on the prevalence of metabolic syndrome and its associated factors in rural northeast China.BMC public health 2014, 14:877.

33. WY F, RW B, EJ B, K C, SE K, DL L, MJ M, LL N, JB S, PW W: Type 2 diabetes and the metabolic syndrome in Japanese Americans.Diabetes research and clinical practice 2000:S73-76.

34. SS O, W K, KT H, EC P, SI J: Alcohol consumption frequency or alcohol intake per drinking session: Which has a larger impact on the metabolic syndrome and its components? Alcohol (Fayetteville, NY) 2018, 71:15-23.

35. H U, S K-K, M Y, F S, K A: Serum hepatic enzyme activity and alcohol drinking status in relation to the prevalence of metabolic syndrome in the general Japanese population.PloS one 2014, 9:e95981.

36. I W: Frequency of heavy alcohol drinking and risk of metabolic syndrome in middle-aged men.Alcoholism, clinical and experimental research 2014, 38:1689-1696.

37. JX M, N C, T A: Metabolic Syndrome Prevalence by Race/Ethnicity and Sex in the United States, National Health and Nutrition Examination Survey, 1988-2012.Preventing chronic disease 2017, 14:E24.

\section{Tables}




\begin{tabular}{|c|c|c|}
\hline \multicolumn{3}{|c|}{ Table1. Sample descriptive characteristic } \\
\hline Variables & Total $(n=9745640)$ & Percentage (\%) \\
\hline \multicolumn{3}{|l|}{ Sex } \\
\hline Female & 4611530 & 47.32 \\
\hline male & 5134110 & 52.68 \\
\hline \multicolumn{3}{|l|}{ Ages } \\
\hline $18-39$ ys & 4412117 & 45.27 \\
\hline $40-59$ ys & 3731961 & 38.29 \\
\hline$\geq 60$ ys & 1601562 & 16.43 \\
\hline \multicolumn{3}{|l|}{ Ethnicity } \\
\hline Han & 2481787 & 25.47 \\
\hline Uyghur & 5645419 & 57.93 \\
\hline Kazak & 799942 & 8.21 \\
\hline Hui & 404253 & 4.15 \\
\hline Kyrgyz & 113716 & 1.17 \\
\hline Mongolian & 79165 & 0.81 \\
\hline Other & 221358 & 2.27 \\
\hline \multicolumn{3}{|c|}{ Household registration } \\
\hline City and town & 2875627 & 29.51 \\
\hline Rural & 6870013 & 70.49 \\
\hline \multicolumn{3}{|c|}{ Geographical location } \\
\hline North & 4364234 & 44.78 \\
\hline South & 5381406 & 55.22 \\
\hline \multicolumn{3}{|l|}{ Education } \\
\hline 6 years or less & 5729947 & 58.79 \\
\hline 7 years or more & 4015693 & 41.21 \\
\hline
\end{tabular}




\begin{tabular}{|c|c|c|c|c|c|c|c|}
\hline \multirow[t]{2}{*}{ Variables } & \multirow{2}{*}{$\begin{array}{l}\text { Overal } \\
(n=9745640)\end{array}$} & \multicolumn{3}{|l|}{ Age } & \multicolumn{3}{|l|}{ Sex } \\
\hline & & $\begin{array}{l}\text { 18-39ys } \\
(n=4412117)\end{array}$ & $\begin{array}{l}\text { 40-59ys } \\
(n=3731961)\end{array}$ & $\begin{array}{l}\geq 60 y s \\
(n=1601562)\end{array}$ & $\begin{array}{l}\text { Men } \\
(n=4611530)\end{array}$ & $\begin{array}{l}\text { Women } \\
(n=5134110)\end{array}$ & \\
\hline Height(cm) & $163.16 \pm 8.92$ & $164.77 \pm 8.79$ & $162.74 \pm 8.52$ & $159.71 \pm 9.1$ & $169.13 \pm 7.05$ & $157.8 \pm 6.77$ & \\
\hline Weight(kg) & $66.14 \pm 12.52$ & $64.68 \pm 12.62$ & $68.45 \pm 12.33$ & $64.79 \pm 11.88$ & $71.14 \pm 12.18$ & $61.65 \pm 11.04$ & \\
\hline BMI(kg/m2) & $24.81 \pm 4.09$ & $23.76 \pm 3.91$ & $25.81 \pm 4.04$ & $25.37 \pm 4.01$ & $24.85 \pm 3.82$ & $24.78 \pm 4.32$ & \\
\hline WC (cm) & $85.39 \pm 12.15$ & $82.37 \pm 11.56$ & $87.87 \pm 12.02$ & $87.96 \pm 12.15$ & $87.79 \pm 11.56$ & $83.23 \pm 12.26$ & \\
\hline $\begin{array}{l}\text { SBP } \\
(\mathrm{mmHg})\end{array}$ & $119.26 \pm 18.11$ & $111.88 \pm 13.25$ & $122.25 \pm 17.84$ & $132.66 \pm 20.51$ & $121.30 \pm 17$ & $117.44 \pm 18.87$ & \\
\hline $\begin{array}{l}\text { DBP } \\
(\mathrm{mmHg})\end{array}$ & $72.82 \pm 11.42$ & $69.37 \pm 9.72$ & $75.11 \pm 11.76$ & $77.01 \pm 12.19$ & $74.1 \pm 11.35$ & $71.67 \pm 11.36$ & \\
\hline $\begin{array}{l}\text { LDL- } \\
\mathrm{C}(\mathrm{mg} / \mathrm{dL})\end{array}$ & $2.45 \pm 0.74$ & $2.3 \pm 0.64$ & $2.57 \pm 0.76$ & $2.61 \pm 0.86$ & $2.47 \pm 0.74$ & $2.44 \pm 0.74$ & \\
\hline $\begin{array}{l}\mathrm{HDL}- \\
\mathrm{C}(\mathrm{mg} / \mathrm{dL})\end{array}$ & $1.41 \pm 0.56$ & $1.39 \pm 0.52$ & $1.43 \pm 0.59$ & $1.45 \pm 0.61$ & $1.39 \pm 0.57$ & $1.44 \pm 0.55$ & \\
\hline $\mathrm{TC}(\mathrm{mg} / \mathrm{dL})$ & $4.36 \pm 1.26$ & $4.08 \pm 1.21$ & $4.55 \pm 1.24$ & $4.69 \pm 1.3$ & $4.37 \pm 1.27$ & $4.35 \pm 1.26$ & \\
\hline $\mathrm{TG}(\mathrm{mg} / \mathrm{dL})$ & $1.43 \pm 1.17$ & $1.3 \pm 1.1$ & $1.56 \pm 1.27$ & $1.51 \pm 1.06$ & $1.57 \pm 1.33$ & $1.31 \pm 0.99$ & \\
\hline $\begin{array}{l}\text { FBG } \\
(\mathrm{mg} / \mathrm{dL})\end{array}$ & $5.28 \pm 1.61$ & $4.98 \pm 1.09$ & $5.43 \pm 1.78$ & $5.78 \pm 2.15$ & $5.32 \pm 1.65$ & $5.24 \pm 1.58$ & \\
\hline $\begin{array}{l}\text { Smoking } \\
\mathrm{n}(\%)^{a}\end{array}$ & 1278212(13.12) & 3795244(13.98) & $3186548(14.61)$ & 1485636(7.24) & $3347159(27.42)$ & $5120269(0.27)$ & \\
\hline $\begin{array}{l}\text { Drinking } \\
\mathrm{n}(\%)^{\mathrm{a}}\end{array}$ & 113618(13.48) & $3768262(14.59)$ & $3187005(14.60)$ & 1476757(7.79) & $3473053(24.69)$ & 4958971(3.41) & \\
\hline $\begin{array}{l}\text { Physical } \\
\text { activity } \\
n(\%)^{a}\end{array}$ & 1370180(14.06) & $3911577(11.34)$ & 3191388(14.48) & $1272497(20.55)$ & $3943753(14.48)$ & 4431709(13.68) & \\
\hline \multirow[t]{2}{*}{ Variables } & Races & & & & & & \\
\hline & $\begin{array}{l}\text { Uyghur } \\
(n=5645419)\end{array}$ & $\begin{array}{l}\text { Han } \\
(n=2481787)\end{array}$ & $\begin{array}{l}\text { Kazak } \\
(n=799942)\end{array}$ & $\begin{array}{l}\text { Hui } \\
(n=404253)\end{array}$ & $\begin{array}{l}\text { Kyrgyz } \\
(n=113716)\end{array}$ & $\begin{array}{l}\text { Mongolian } \\
(n=79165)\end{array}$ & $\begin{array}{l}\text { Other } \\
(n=221358)\end{array}$ \\
\hline Height(cm) & $162.24 \pm 8.95$ & $164.18 \pm 8.64$ & $165.13 \pm 8.93$ & $164.31 \pm 8.63$ & $163.72 \pm 9.09$ & $164.72 \pm 8.84$ & $165.16 \pm 8.72$ \\
\hline Weight(kg) & $65.29 \pm 12.54$ & $66.44 \pm 11.69$ & $69.51 \pm 13.78$ & $68.34 \pm 12.43$ & $65.28 \pm 12.45$ & $69.56 \pm 13.37$ & $67.51 \pm 13.03$ \\
\hline BMI(kg/m2) & $24.79 \pm 4.26$ & $24.59 \pm 3.52$ & $25.45 \pm 4.45$ & $25.28 \pm 3.95$ & $24.33 \pm 4.07$ & $25.60 \pm 4.28$ & $24.68 \pm 3.98$ \\
\hline $\mathrm{WC}(\mathrm{cm})$ & $85.8 \pm 12.5$ & $84.26 \pm 10.85$ & $86.04 \pm 13.43$ & $85.91 \pm 11.71$ & $84.31 \pm 11.82$ & $86.48 \pm 12.82$ & $84.65 \pm 11.92$ \\
\hline $\mathrm{SBP}(\mathrm{mmHg})$ & $117.38 \pm 18.24$ & $122.11 \pm 16.87$ & $122.75 \pm 19.36$ & $121.65 \pm 18.19$ & $114.31 \pm 17.35$ & $122.58 \pm 18.75$ & $119.86 \pm 16.62$ \\
\hline $\mathrm{DBP}(\mathrm{mmHg})$ & $71.44 \pm 11.47$ & $74.84 \pm 10.65$ & $75.01 \pm 12.12$ & $74.59 \pm 11.4$ & $73.08 \pm 11.46$ & $75.23 \pm 11.68$ & $73.42 \pm 10.48$ \\
\hline $\begin{array}{l}\mathrm{LDL}- \\
\mathrm{C}(\mathrm{mg} / \mathrm{dL})\end{array}$ & $2.42 \pm 0.65$ & $2.51 \pm 0.89$ & $2.44 \pm 0.75$ & $2.47 \pm 0.79$ & $2.49 \pm 0.74$ & $2.47 \pm 0.63$ & $2.57 \pm 0.78$ \\
\hline $\begin{array}{l}\mathrm{HDL}- \\
\mathrm{C}(\mathrm{mg} / \mathrm{dL})\end{array}$ & $1.39 \pm 0.53$ & $1.45 \pm 0.66$ & $1.47 \pm 0.45$ & $1.40 \pm 0.49$ & $1.41 \pm 0.56$ & $1.47 \pm 0.98$ & $1.38 \pm 0.44$ \\
\hline $\mathrm{TC}(\mathrm{mg} / \mathrm{dL})$ & $4.22 \pm 1.22$ & $4.58 \pm 1.34$ & $4.58 \pm 1.27$ & $4.44 \pm 1.19$ & $4.36 \pm 1.27$ & $4.49 \pm 1.27$ & $4.52 \pm 1.19$ \\
\hline $\mathrm{TG}(\mathrm{mg} / \mathrm{dL})$ & $1.40 \pm 1.11$ & $1.58 \pm 1.32$ & $1.24 \pm 1.00$ & $1.5 \pm 1.23$ & $1.25 \pm 0.91$ & $1.27 \pm 1.05$ & $1.48 \pm 1.2$ \\
\hline $\mathrm{FBG}(\mathrm{mg} / \mathrm{dL})$ & $5.22 \pm 1.59$ & $5.41 \pm 1.74$ & $5.20 \pm 1.22$ & $5.60 \pm 1.85$ & $5.21 \pm 1.12$ & $5.23 \pm 1.31$ & $5.17 \pm 1.55$ \\
\hline $\begin{array}{l}\text { Smoking } \\
n(\%)^{a}\end{array}$ & 4896487(13.27) & 2203758(11.20) & 663934(17.00) & $364453(9.85)$ & $87390(23.15)$ & 62582(20.95) & 4896487(13.27) \\
\hline $\begin{array}{l}\text { Drinking } \\
\mathrm{n}(\%)^{\mathrm{a}}\end{array}$ & 4950831(12.30) & 2121181(14.53) & $686531(14.18)$ & $378033(6.49)$ & $86713(23.75)$ & 63742(19.48) & $4950831(12.30)$ \\
\hline
\end{tabular}




\begin{tabular}{|c|c|c|c|c|c|c|c|}
\hline $\begin{array}{l}\text { Physical } \\
\text { activity } \\
\mathrm{n}(\%)^{\mathrm{a}}\end{array}$ & $5193222(8.01)$ & $1839242(25.89)$ & 706576(11.67) & 339318(16.06) & $105399(7.31)$ & $62524(21.02)$ & $5193222(8.01)$ \\
\hline \multirow[t]{2}{*}{ Variables } & \multicolumn{2}{|c|}{ Geographical location } & \multicolumn{2}{|l|}{ Education } & \multicolumn{3}{|c|}{ Household registration } \\
\hline & $\begin{array}{l}\text { North } \\
(n=4364234)\end{array}$ & $\begin{array}{l}\text { South } \\
(n=5381406)\end{array}$ & $\begin{array}{l}\leq 6 y s \\
(n=5729947)\end{array}$ & $\begin{array}{l}\geq 7 y s \\
(n=4015693)\end{array}$ & $\begin{array}{l}\text { City and town } \\
(n=2875627)\end{array}$ & $\begin{array}{l}\text { Rural } \\
(n=6870013)\end{array}$ & \\
\hline Height(cm) & $164.63 \pm 8.68$ & $161.97 \pm 8.94$ & $164.34 \pm 8.59$ & $161.48 \pm 9.12$ & $164.66 \pm 8.63$ & $162.53 \pm 8.97$ & \\
\hline Weight(kg) & $67.92 \pm 12.54$ & $64.69 \pm 12.31$ & $66.5 \pm 12.61$ & $65.62 \pm 12.37$ & $67.3 \pm 12.51$ & $65.66 \pm 12.49$ & \\
\hline BMI (kg/m2) & $25.02 \pm 3.97$ & $24.64 \pm 4.18$ & $24.58 \pm 4.01$ & $25.15 \pm 4.19$ & $24.78 \pm 3.98$ & $24.83 \pm 4.14$ & \\
\hline$W C(\mathrm{~cm})$ & $85.47 \pm 11.95$ & $85.33 \pm 12.31$ & $84.71 \pm 11.98$ & $86.36 \pm 12.33$ & $85.1 \pm 11.96$ & $85.52 \pm 12.23$ & \\
\hline $\begin{array}{l}\text { SBP } \\
(\mathrm{mmHg})\end{array}$ & $122.34 \pm 17.88$ & $116.77 \pm 17.92$ & $117.2 \pm 16.69$ & $122.22 \pm 19.6$ & $120.02 \pm 17$ & $118.95 \pm 18.55$ & \\
\hline $\begin{array}{l}\text { DBP } \\
(\mathrm{mmHg})\end{array}$ & $74.67 \pm 11.24$ & $71.33 \pm 11.35$ & $72.21 \pm 11.03$ & $73.7 \pm 11.9$ & $73.58 \pm 10.84$ & $72.51 \pm 11.64$ & \\
\hline $\begin{array}{l}\text { LDL- } \\
\mathrm{C}(\mathrm{mg} / \mathrm{dL})\end{array}$ & $2.5 \pm 0.84$ & $2.42 \pm 0.65$ & $2.42 \pm 0.74$ & $2.51 \pm 0.74$ & $2.49 \pm 0.85$ & $2.44 \pm 0.69$ & \\
\hline $\begin{array}{l}\mathrm{HDL}- \\
\mathrm{C}(\mathrm{mg} / \mathrm{dL})\end{array}$ & $1.44 \pm 0.6$ & $1.39 \pm 0.53$ & $1.41 \pm 0.58$ & $1.41 \pm 0.53$ & $1.43 \pm 0.62$ & $1.41 \pm 0.53$ & \\
\hline $\mathrm{TC}(\mathrm{mg} / \mathrm{dL})$ & $4.57 \pm 1.29$ & $4.20 \pm 1.22$ & $4.31 \pm 1.24$ & $4.44 \pm 1.29$ & $4.48 \pm 1.36$ & $4.31 \pm 1.22$ & \\
\hline $\mathrm{TG}(\mathrm{mg} / \mathrm{dL})$ & $1.48 \pm 1.22$ & $1.40 \pm 1.12$ & $1.43 \pm 1.19$ & $1.43 \pm 1.13$ & $1.53 \pm 1.28$ & $1.39 \pm 1.12$ & \\
\hline $\mathrm{FBG}(\mathrm{mg} / \mathrm{dL})$ & $5.37 \pm 1.7$ & $5.21 \pm 1.53$ & $5.26 \pm 1.43$ & $5.32 \pm 1.84$ & $5.25 \pm 1.77$ & $5.3 \pm 1.54$ & \\
\hline $\begin{array}{l}\text { Smoking } \\
\mathrm{n}(\%)^{a}\end{array}$ & $3802246(12.88)$ & $4665182(13.31)$ & $3563108(11.27)$ & 4904320(14.41) & 2564803(10.81) & $5902625(14.08)$ & \\
\hline $\begin{array}{l}\text { Drinking } \\
\mathrm{n}(\%)^{a}\end{array}$ & $3709019(15.01)$ & 4723005(12.23) & $500965(12.48)$ & $812651(14.18)$ & 2450668(14.78) & 5981356(12.94) & \\
\hline $\begin{array}{l}\text { Physical } \\
\text { activity } \\
\mathrm{n}(\%)^{a}\end{array}$ & 4915843(8.65) & $3459619(20.73)$ & $582697(14.51)$ & 787481(13.74) & 2124404(26.12) & 6251058(9.01) & \\
\hline
\end{tabular}

a Using a Chi-squared test.

Data are expressed as the mean \pm SD or as $\mathrm{n}(\%)$ BMI body mass index, WC waist circumference, SBP systolic blood pressure, DBP diastolic blood pressure, TG triglyceride, LDL-C low-density lipoprotein cholesterol, HDL-C high-density lipoprotein cholesterol, FPG fasting plasma glucose.

All $P$ values $<0.0001$. 


\begin{tabular}{|c|c|c|c|c|c|c|}
\hline \multirow[t]{2}{*}{ Variables } & \multirow{2}{*}{$\begin{array}{l}\text { Metabolic } \\
\text { syndrome }\end{array}$} & \multicolumn{5}{|c|}{ Percentage with MetS Component } \\
\hline & & $\begin{array}{l}\text { Central } \\
\text { obesity }\end{array}$ & $\begin{array}{l}\text { High } \\
\text { triglycerides }\end{array}$ & $\begin{array}{l}\text { Low high-density lipoprotein } \\
\text { cholesterol }\end{array}$ & $\begin{array}{l}\text { Elevated blood } \\
\text { pressure }\end{array}$ & $\begin{array}{l}\text { Elevated fasting } \\
\text { plasma } \\
\text { glucose }\end{array}$ \\
\hline Total(\%) & 20.85 & 51.71 & 23.71 & 4.68 & 23.16 & 26.59 \\
\hline \multicolumn{7}{|l|}{ Sex } \\
\hline Female (\%) & 21.56 & 60.83 & 19.37 & 5.69 & 21.70 & 28.27 \\
\hline Male (\%) & 20.06 & 41.56 & 28.53 & 9.89 & 24.81 & 25.80 \\
\hline \multicolumn{7}{|l|}{ Ages } \\
\hline $18-39(\%)$ & 9.56 & 40.79 & 18.66 & 7.46 & 6.71 & 16.94 \\
\hline $40-59(\%)$ & 26.32 & 60.86 & 28.15 & 7.30 & 28.12 & 30.48 \\
\hline$\geq 60 \rrbracket(\%)$ & 39.22 & 60.48 & 27.24 & 9.15 & 56.96 & 44.14 \\
\hline \multicolumn{7}{|l|}{ Races } \\
\hline Uyghur (\%) & 18.56 & 52.80 & 22.98 & 7.88 & 20.69 & 23.89 \\
\hline $\operatorname{Han}(\%)$ & 26.39 & 48.93 & 27.75 & 8.11 & 26.49 & 32.69 \\
\hline Kazak (\%) & 17.98 & 52.47 & 16.78 & 4.53 & 26.96 & 23.84 \\
\hline Hui (\%) & 28.19 & 54.85 & 26.04 & 8.09 & 26.21 & 35.68 \\
\hline Kyrgyz (\%) & 14.44 & 47.01 & 16.69 & 7.79 & 19.55 & 25.57 \\
\hline Mongolian (\%) & 17.87 & 55.94 & 17.74 & 3.53 & 27.18 & 24.17 \\
\hline Other (\%) & 18.61 & 47.51 & 23.45 & 9.66 & 30.13 & 21.69 \\
\hline \multicolumn{7}{|c|}{ Permanent address } \\
\hline $\begin{array}{l}\text { City and town } \\
(\%)\end{array}$ & 23.03 & 51.12 & 26.65 & 7.94 & 23.81 & 26.56 \\
\hline Rural (\%) & 19.94 & 51.96 & 22.48 & 7.57 & 22.90 & 26.61 \\
\hline \multicolumn{7}{|l|}{ Area } \\
\hline North (\%) & 24.78 & 52.18 & 24.91 & 7.18 & 27.20 & 30.28 \\
\hline South (\%) & 17.66 & 51.33 & 22.73 & 8.08 & 19.90 & 23.60 \\
\hline \multicolumn{7}{|l|}{ Education } \\
\hline $\begin{array}{l}6 \text { years or less } \\
(\%)\end{array}$ & 18.26 & 48.92 & 23.51 & 7.34 & 17.49 & 24.89 \\
\hline $\begin{array}{l}7 \text { years or more } \\
(\%)\end{array}$ & 24.54 & 55.70 & 23.98 & 8.16 & 31.27 & 29.01 \\
\hline \multicolumn{7}{|l|}{ Smoking } \\
\hline Yes (\%) & 20.45 & 44.24 & 32.00 & 8.02 & 21.25 & 27.90 \\
\hline No (\%) & 20.94 & 52.84 & 22.45 & 7.62 & 23.46 & 26.39 \\
\hline \multicolumn{7}{|l|}{ Drinking } \\
\hline Yes (\%) & 20.851 & 46.09 & 30.35 & 9.01 & 23.37 & 26.50 \\
\hline No (\%) & 20.852 & 52.59 & 22.67 & 7.47 & 23.14 & 26.61 \\
\hline \multicolumn{7}{|l|}{ Physical activity } \\
\hline Yes (\%) & 25.80 & 52.85 & 27.11 & 8.96 & 31.46 & 28.64 \\
\hline No (\%) & 20.04 & 51.53 & 23.15 & 7.47 & 21.81 & 26.26 \\
\hline
\end{tabular}

All $P$ values $<0.0001$. Data are expressed as $\%$.

Figures 


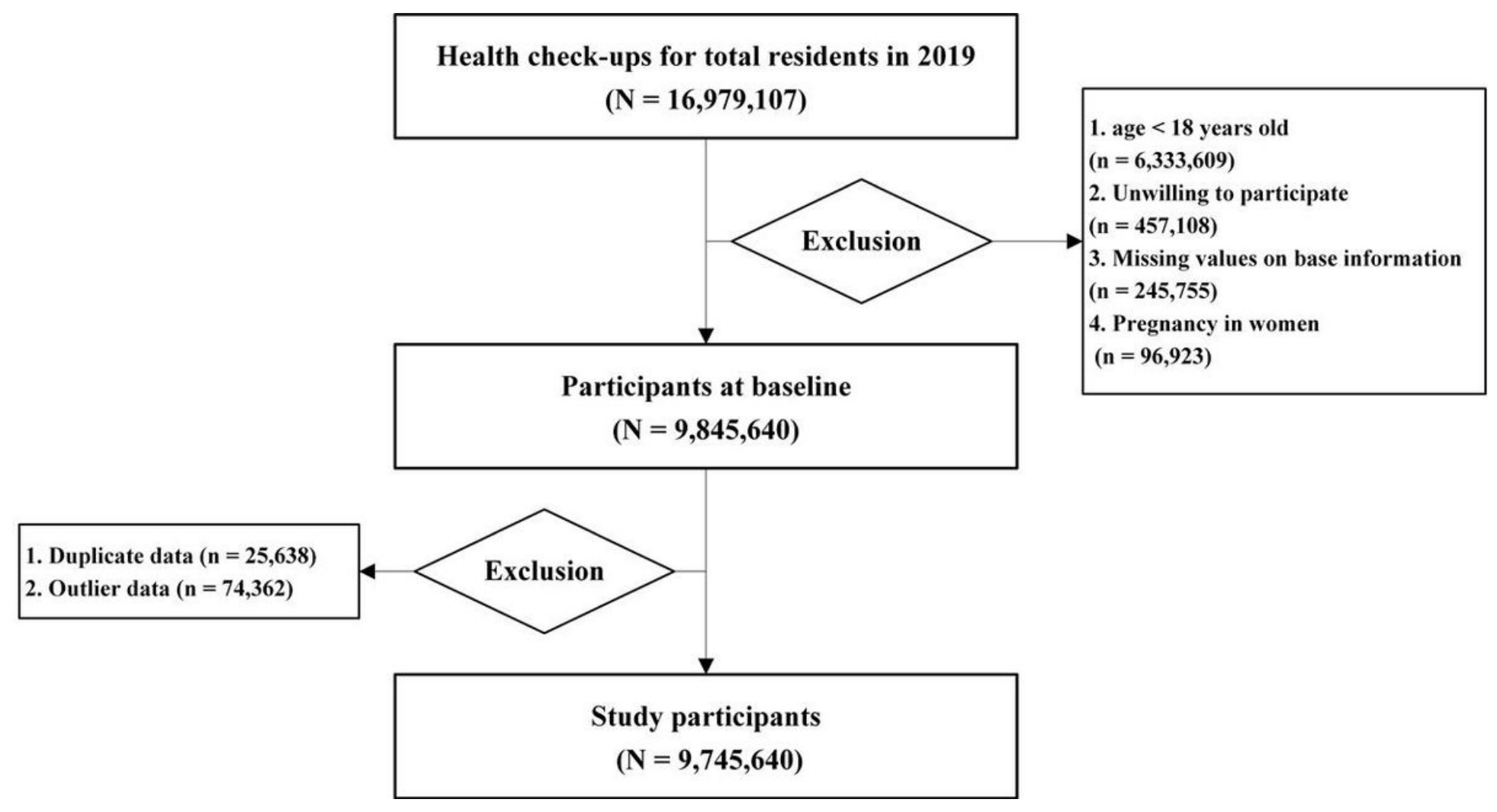

Figure 1

Flow chart of the study

\section{Variable}

Male vs Female

$40-59$ vs $18-39$ ys

>= 60 vs $18-39$ ys

Uyghur vs Kyrgyz

Han vs Kyrgyz

Kazak vs Kyrgyz

Hui vs Kyrgyz

Mongolian vs Kyrgyz

Other vs Kyrgyz

City and town vs Rural

North vs South

Education $>=7$ vs $<=6$ ys

Smoker vs Nonsmoker

Drinker vs Nondrinking

Sedentary vs Acitive

\section{OR(C195\%)}

$0.84(0.84,0.85)$

$3.25(3.25,3.28)$

$5.93(5.91,5.97)$

$1.35(1.33,1.37)$

$1.27(1.24,1.29)$

$0.97(0.96,0.99)$

$1.63(1.61,1.67)$

$0.91(0.89,0.94)$

$1.02(1.00,1.04)$

$1.04(1.03,1.04)$

$1.34(1.33,1.34)$

$0.98(0.98,0.99)$

$1.15(1.15,1.16)$

$1.12(1.11,1.12)$

$0.90(0.90,0.91)$

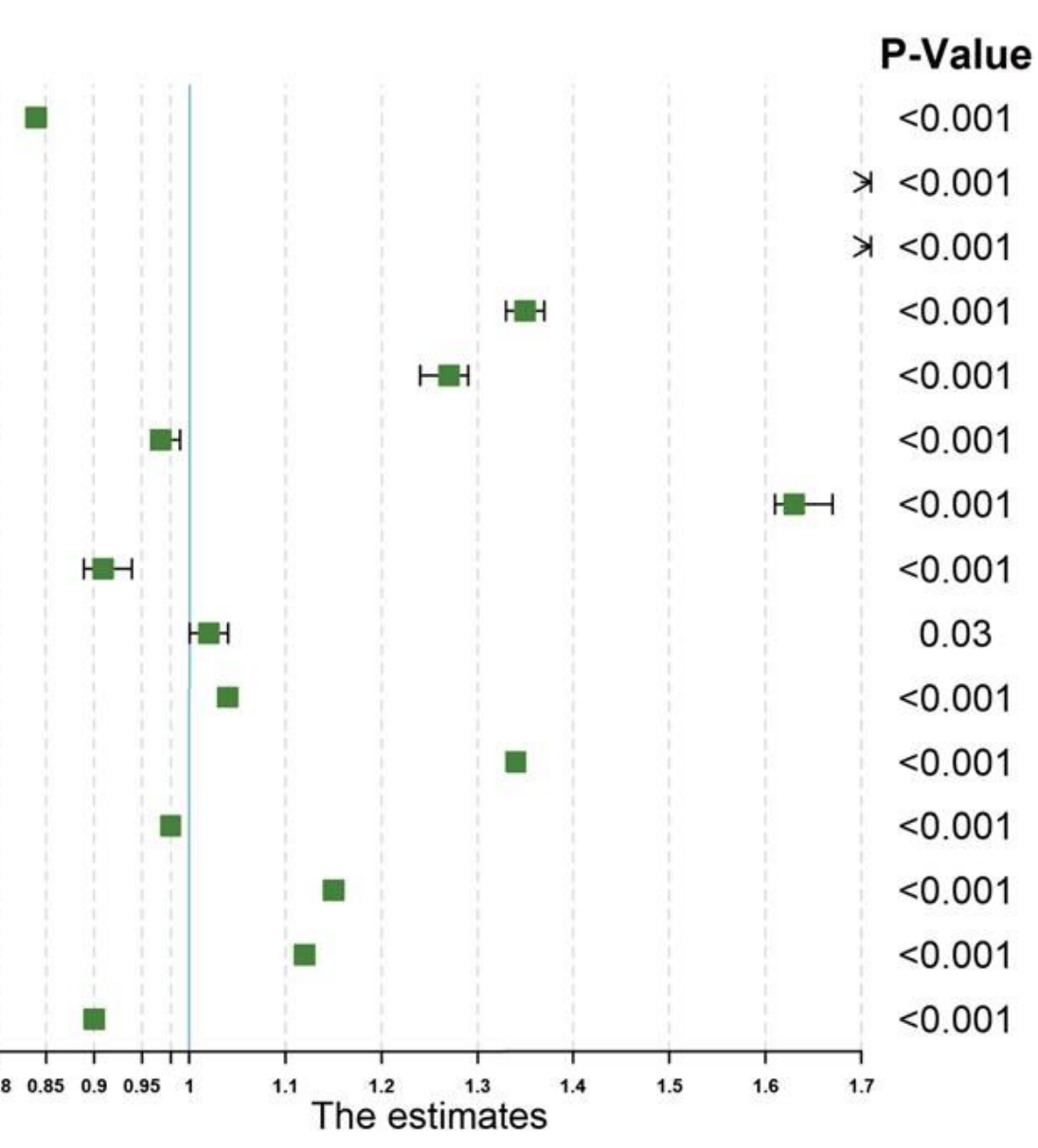

Figure 2 


\section{Variable}

Male vs Female

40-59 vs $18-39$ ys

$>=60$ vs $18-39$ ys

Uyghur vs Kyrgyz

Han vs Kyrgyz

Kazak vs Kyrgyz

Hui vs Kyrgyz

Mongolian vs Kyrgyz

Other vs Kyrgyz

City and town vs Rural

North vs South

Education $>=7$ vs $<=6$ ys

Smoker vs Nonsmoker

Drinker vs Nondrinking

Sedentary vs Acitive

\section{OR(Cl95\%)}

$0.42(0.42,0.42) k$

$2.46(2.45,2.47)$

$2.56(2.56,2.58)$

$1.27(1.25,1.29)$

$0.79(0.79,0.81)$

$1.11(1.09,1.12)$

$1.16(1.14,1.18)$

$1.19(1.17,1.21)$

$0.90(0.89,0.91)$

$1.03(1.03,1.03)$

$1.11(1.10,1.11)$

$0.98(0.98,0.99)$

$1.13(1.12,1.13)$

$1.12(1.12,1.13)$

$0.95(0.94,0.95)$
P-Value

$<0.001$

$\rightarrow<0.001$

$\Rightarrow \quad<0.001$

$<0.001$

$<0.001$

$<0.001$

$<0.001$

$<0.001$

$<0.001$

$<0.001$

$<0.001$

$<0.001$

$<0.001$

$<0.001$

$<0.001$

Figure 3

Odds Ratios and $95 \%$ Cls for the Associations of Central Obesity With population and health behavior characteristics

\section{Variable}

Male vs Female

$40-59$ vs $18-39$ ys

$>=60$ vs $18-39$ ys

Uyghur vs Kyrgyz

Han vs Kyrgyz

Kazak vs Kyrgyz

Hui vs Kyrgyz

Mongolian vs Kyrgyz

Other vs Kyrgyz

City and town vs Rural

North vs South

Education $>=7$ vs $<=6$ ys

Smoker vs Nonsmoker

Drinker vs Nondrinking

Sedentary vs Acitive
OR(Cl95\%)

$1.54(1.53,1.54)$

$1.72(1.71,1.72)$

$1.65(1.64,1.65)$

$1.58(1.55,1.60)$

$1.62(1.58,1.64)$

$0.96(0.94,0.98)$

$1.67(1.64,1.70)$

$0.95(0.93,0.98)$

$1.34(1.31,1.36)$

$1.17(1.16,1.17)$

$1.06(1.05,1.06)$

$0.94(0.94,0.94)$

$1.27(1.27,1.28)$

$1.11(1.10,1.11)$

$0.92(0.92,0.93)$
P-Value

$<0.001$

$<0.001$

$<0.001$

$<0.001$

$<0.001$

$<0.001$

$<0.001$

$<0.001$

$<0.001$

$<0.001$

$<0.001$

$<0.001$

$<0.001$

$<0.001$

$<0.001$ 


\section{Variable}

Male vs Female

40-59 vs $18-39$ ys

$>=60$ vs $18-39$ ys

Uyghur vs Kyrgyz

Han vs Kyrgyz

Kazak vs Kyrgyz

Hui vs Kyrgyz

Mongolian vs Kyrgyz

Other vs Kyrgyz

City and town vs Rural

North vs South

Education $>=7$ vs $<=6$ ys

Smoker vs Nonsmoker

Drinker vs Nondrinking

Sedentary vs Acitive
OR(C195\%)

$$
\begin{aligned}
& 1.93(1.92,1.94) \\
& 0.97(0.96,0.97) \\
& 1.15(1.14,1.16) \\
& 1.02(0.99,1.04) \\
& 1.07(1.05,1.10) \\
& 0.63(0.61,0.64) k \\
& 1.11(1.08,1.14) \\
& 0.46(0.45,0.49) k \\
& 1.21(1.17,1.24) \\
& 1.02(1.01,1.03) \\
& 0.88(0.87,0.89)
\end{aligned}
$$

$1.09(1.09,1.10)$

$0.74(0.73,0.75) k$

$1.09(1.08,1.10)$

$0.85(0.85,0.86)$

\subsection{5}




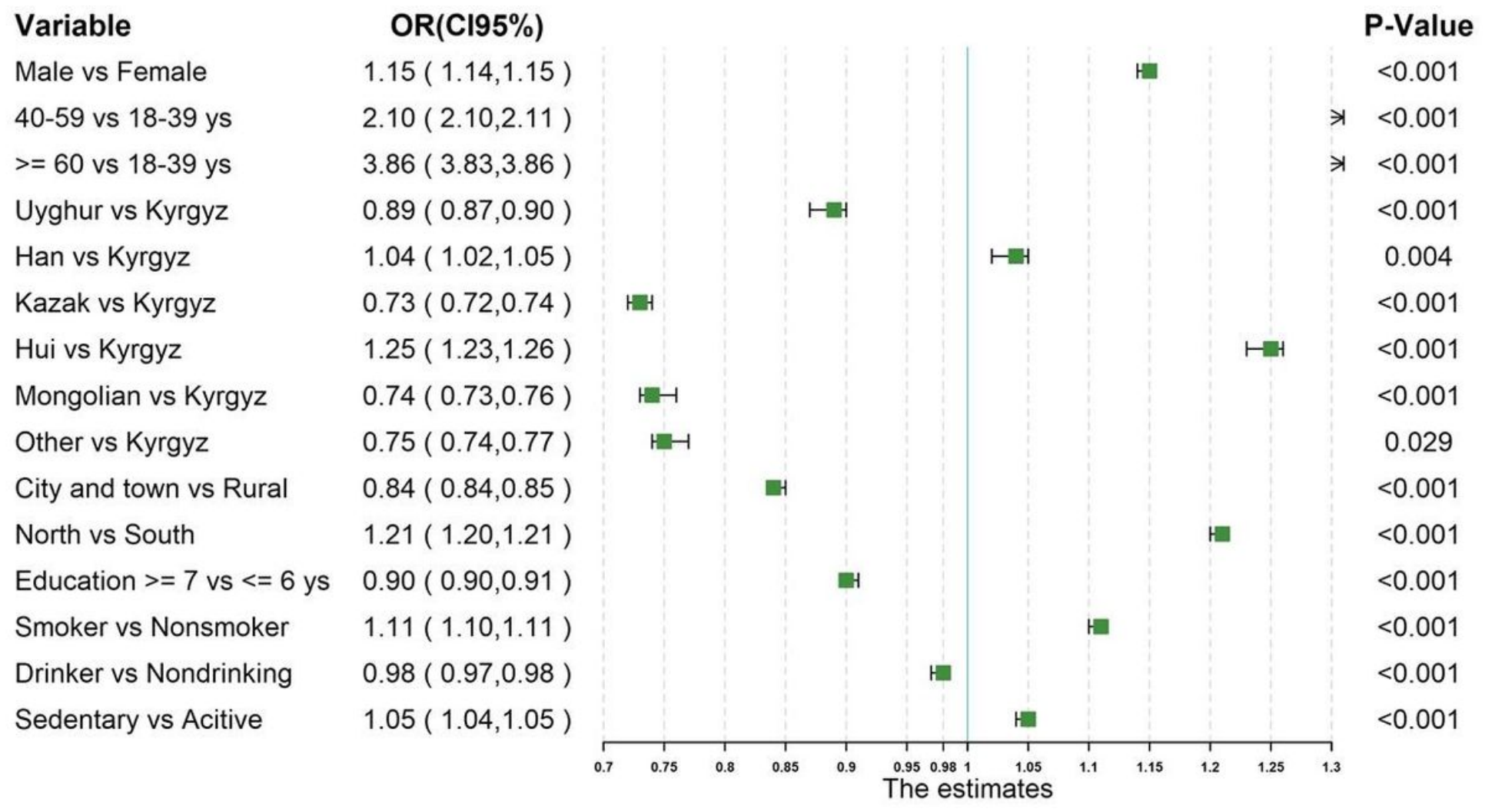

Figure 7

Odds Ratios and 95\% Cls for the Associations of Elevated-FPG with population and health behavior characteristics 